\title{
Bursa Koşullarında Ana Ürün Olarak Bazı Susam (Sesamum indicum L.) Genotiplerinin Verim Özelliklerinin İncelenmesi
}

\author{
Mehmet ÖZ \\ ${ }^{1}$ Uludağ Üniversitesi Mustafakemalpaşa Meslek Yüksekokulu, 16500 Mustafakemalpaşa, Bursa. \\ $\bowtie$ : momer@uludag.edu.tr
}

Geliş (Received): 03.11.2017

Kabul (Accepted): 15.12.2017

\begin{abstract}
ÖZET: Bu çalışma, 2015-2016 yıllarında, Uludağ Üniversitesi Mustafakemalpaşa Meslek Yüksek Okulu deneme alanında ana ürün olarak 16 farklı susam genotipinin ana ürün olarak performansını belirlemek amacıyla iki yıllık olarak yürütülmüştür. Çalışma tesadüf blokları deneme deseninde 3 tekerrürlü olarak düzenlenmiştir. Denemede Gölmarmara, Boydak, Sarısu, Tanas, Muganlı-57, Cumhuriyet 99, Osmanlı 99, Tan 99, Kepsut 99, Hatipoğlu, Aslanbey, Baydar 2001, Batem Aksu, Özberk-82, Orhangazi 99 ve yerel hat Pakistan genotipleri kullanılmıştır. Çalışmada bitki boyu, ana dala bağlı yan dal sayısı, bitkide kapsül sayısı, kapsülde tane sayısı, 1000 tane ağırlığı, bitki başına tohum verimi ve dekara tohum verimi komponentleri incelenmiştir. İki yılın ortalaması sonuçlara göre, tohum verimi bakımından $1989 \mathrm{~kg} / \mathrm{ha}$ ile Boydak, $1968 \mathrm{~kg} / \mathrm{ha}$ ile de Gölmarmara ve $1753 \mathrm{~kg} / \mathrm{ha}$ ile Aslanbey çeşitleri en yüksek değerleri vermişlerdir. İkinci yılın tohum verimi ilk yllın tohum veriminden daha yüksek olmuştur (1745 ve $1480 \mathrm{~kg} / \mathrm{ha}$ ). İncelenen özellikleri minimum ve maksimum değerleri bitki boyu için 121.6-157.5 $\mathrm{cm}$, ana dala bağlı yan dal sayısı için 2.0-6.7 adet, bitkide kapsül sayısı için 65.8-119.5 adet, kapsülde tane sayısı için 53.0-67.8 adet, 1000 tane ağırlı̆ 1 için $3.1-4.1 \mathrm{~g}$ ve tohum verimi için de $103.5-198.9 \mathrm{~kg} / \mathrm{da}$ arasında değişim göstermiştir. Tohum verimi bakımından en yüksek değeri veren Boydak çeşidi yöre için önerilmektedir.

Anahtar Kelimeler: Susam, Adaptasyon, Verim ve verim komponentleri.
\end{abstract}

\section{Investigation of Yield Traits of Some Sesame (Sesame indicum L.) Genotypes as Main Crop in Bursa Conditions}

\begin{abstract}
This study was carried out to determine the performance of sixteen different sesame varieties as the main crop, at the Uludag University Mustafakemalpasa Vocational School trial field, in years 2015 and 2016. Varieties of Golmarmara, Boydak, Sarisu, Tanas, Muganli-57, Cumhuriyet 99, Osmanli 99, Tan 99, Kepsut 99, Hatipoglu, Aslanbey, Baydar 2001, Batem Aksu, Ozberk-82, Orhangazi 99, and local line Pakistan were used as plant material in the trials. In this study, components of plant height, branch number attached to the main stem, number of capsules per plant, number of seed per capsule, 1000 seed weight and seed yield were examined. As an average of two years, the varieties Boydak, Golmarmara and Aslanbey produced the higher seed yield values with $1989.0 \mathrm{~kg}$ ha-1, $1968.0 \mathrm{~kg}$ ha-1 and $1753.0 \mathrm{~kg}$ ha-1, respectively. Mean seed yield in the second year was higher than the first year's mean (1745.0 vs. $1480.0 \mathrm{~kg}$ ha-1). Minimum and maximum values of evaluated traits were changed betwen 121.6 and $157.5 \mathrm{~cm}$ for plant height, between 2.0 and 6.7 for branch number attached to the main stem, between 65.8 and 119.5 for number of capsules per plant, between 53.0 and 67.8 for number of seed per capsule, between 3.1 and $4.1 \mathrm{~g}$ for 1000 seed weight and between 1035.0 and $1989.0 \mathrm{~kg}$ per hectare for seed yield. Key Words: Sesame, Adaptation, Yield and Yield Components
\end{abstract}

\section{GíRIŞ}

Susam, dünyada kültüre alınan ilk yağlı tohum bitkisi olması nedeniyle köklü bir geçmişe ve zengin bir kullanım alanına sahiptir. Beş bin yılı aşkın bir süredir insanlar tarafından kullanılan bu bitki Türk kültüründe de çok önemli bir yere sahiptir. Tohumlarının \% 50-60 oranındaki yağ içeriği ve elde edilen kaliteli yağının yanı sıra tahin ve tahin helvası imali en yaygın kullanım alanıdır. İnsan beslenmesi için ideal bir yağ elde edilebilmesine karşın susam hasat ve harmanının zahmetli oluşu ve bunun maliyeti artırıcı etkisi nedeniyle Türkiye'de yağ sanayinde fazlaca kullanılamamaktadır (Arslan ve ark., 2007; Uzun ve ark., 2008; Şahin, 2014)

Özellikle, makineli hasada uygun ve kapsüllerini çatlatmayan yüksek verimli çeşitlerin yetersiz ve mevcutların adaptasyon alanlarının sınırlı oluşu susam tarımının dünyada istenilen düzeyde gelişmesini engellemektedir. $\mathrm{Bu}$ nedenle de susam tarımı olması gereken düzeye gelememektedir (Baydar, 2001). Ayrıca Gıda Tarım ve Hayvancılık Bakanlığı birçok yağlı tohum üretimini teşvik ederken susam bu bitkilerin dışında tutulmuştur (Anonim, 2015).

Dünyada 9.4 milyon ha gibi geniş bir alanda üretilmekle birlikte, tohum veriminin düşük olması nedeniyle (ortalama $51.4 \mathrm{~kg} / \mathrm{da}$ ) üretim 4.8 milyon ton gibi düşük bir seviyede kalmaktadır. Dünya toplam susam üretiminin \%50'si Asya, \%43.7'si Afrika ve \%3.8'i de Amerika kıtasında üretilmektedir. Dünyada en yüksek üretim yapan ülkeler Hindistan, Sudan, Myanmar, Çin ve Nijerya'dır (Anonim, 2017).

Ülkemizde susam ekim alanı 1989 yılında 976000 dekar iken 2016 yllında 289000 dekara düşmüştür. Üretim de 45000 tondan 19500 tona azalmıştır. Ortalama verim ise dekara 38 kg'dan $67 \quad \mathrm{~kg}$ 'a yükselmiştir (Anonim, 2017).

Türkiye, Nijerya başta olmak üzere Hindistan, Etiyopya, Pakistan, Uganda ve çoğu Afrika ülkesi 
olmak üzere toplam 27 ülkeden susam ithalatı gerçekleştirmektedir (Kaynak?). Daha önceleri Çin, Hindistan ve Pakistan gibi birkaç Asya ülkesi ve Afrika'nın geleneksel susam üreticileri ile sınırlı olan susam ithalatı 2011'e gelindiğinde Meksika'dan Bangladeş'e, Paraguay'dan Özbekistan'a kadar çok geniş bir sahayı kapsar hale gelmiştir. Hızla artan susam ithalatının doğal bir sonucu olarak ödenen dövizde de dikkat çekici artışlar yaşanmıştır. Örneğin; 1995'teki susam ithalatının maliyeti 24 milyon \$ iken 2005'te 64 milyon \$'a ve 2011'de de 140 milyon \$'a çıkmıştır (Şahin, 2014).

Tan (2011), Menemen koşullarında susamda yaptığg çalışmasında 1000 tane ağırlığının 3.37-3.67 g, tohum veriminin $181-254 \mathrm{~kg} / \mathrm{da}$ ve bitki boyunun 114.0-133.7 $\mathrm{cm}$ arasında değiștiğini bildirmiștir. Silme ve Çağırgan (2009) bitki boylarını 102.1-177.9, bitki başına kapsül sayılarını 28.0-62.5 adet, kapsülde tane sayılarını 59.771.9 adet, 1000 tane ağırlıklarının 2.3-4.3 g ve tohum verimlerinin de 17.7-76.9 $\mathrm{kg} / \mathrm{da}$ arasinda belirlemişlerdir.

Bitki boyu $83.1 \mathrm{~cm}$, dal sayısı 4.4 adet/bitki, bitkide kapsül sayısı 38.7 adet, kapsülde tohum sayısı 52.8 adet, 1000 tane ağırlığ $2.0 \mathrm{~g}$ ve tohum verimi de $238.8 \mathrm{~kg} / \mathrm{ha}$ olarak rapor edilmiştir (Alam Sarkar ve ark., 2007).
$\mathrm{Bu}$ çalışmanın amacı, farklı susam genotiplerinin Bursa'nın Mustafakemalpaşa ilçesi ana ürün koşullarındaki verim ve verim unsurlarını incelemektir.

\section{MATERYAL ve YÖNTEM}

$\mathrm{Bu}$ çalışma, 2015-2016 yıllarında, Uludağ Üniversitesi Mustafakemalpaşa Meslek Yüksek Okulu deneme alanında $\left(40^{\circ} 02^{\prime} \mathrm{N}, 2^{\circ} 8^{\circ} 23^{\prime} \mathrm{E}\right) 16$ farklı susam genotipinin (Gölmarmara, Boydak, Sarısu, Tanas, Muganl1-57, Cumhuriyet 99, Osmanlı 99, Tan 99, Kepsut 99, Hatipoğlu, Aslanbey, Baydar 2001, Batem Aksu, Özberk-82, Orhangazi 99 ve yerel hat Pakistan) ana ürün koşullarındaki performanslarını belirlemek amacıyla iki yıllık olarak yürütülmüştür. Çalışma tesadüf blokları deneme deseninde 3 tekerrürlü olarak düzenlenmiştir. Parsellerin uzunluğu $5 \mathrm{~m}$, eni 1.8 m'dir. Her parselde 4 sıra yer almıştır. Sıra arası sıklığ $45 \mathrm{~cm}$, sıra üzeri sıklığı ise $15 \mathrm{~cm}$ olarak kullanılmıştır.

Denemenin kurulduğu yıllara ve uzun y1llara ait toplam yağış ve ortalama hava sicaklığı değerleri Çizelge 1 ve 2'de verilmiştir. Deneme üzerinde etkili olan ayların yağış dağılımları incelendiğinde Temmuz ve Ağustos ayları yağış ortalamalarının uzun yıllardan daha az, Eylül ayı ortalamasının ise belirgin miktarda fazla olduğu görülmektedir.

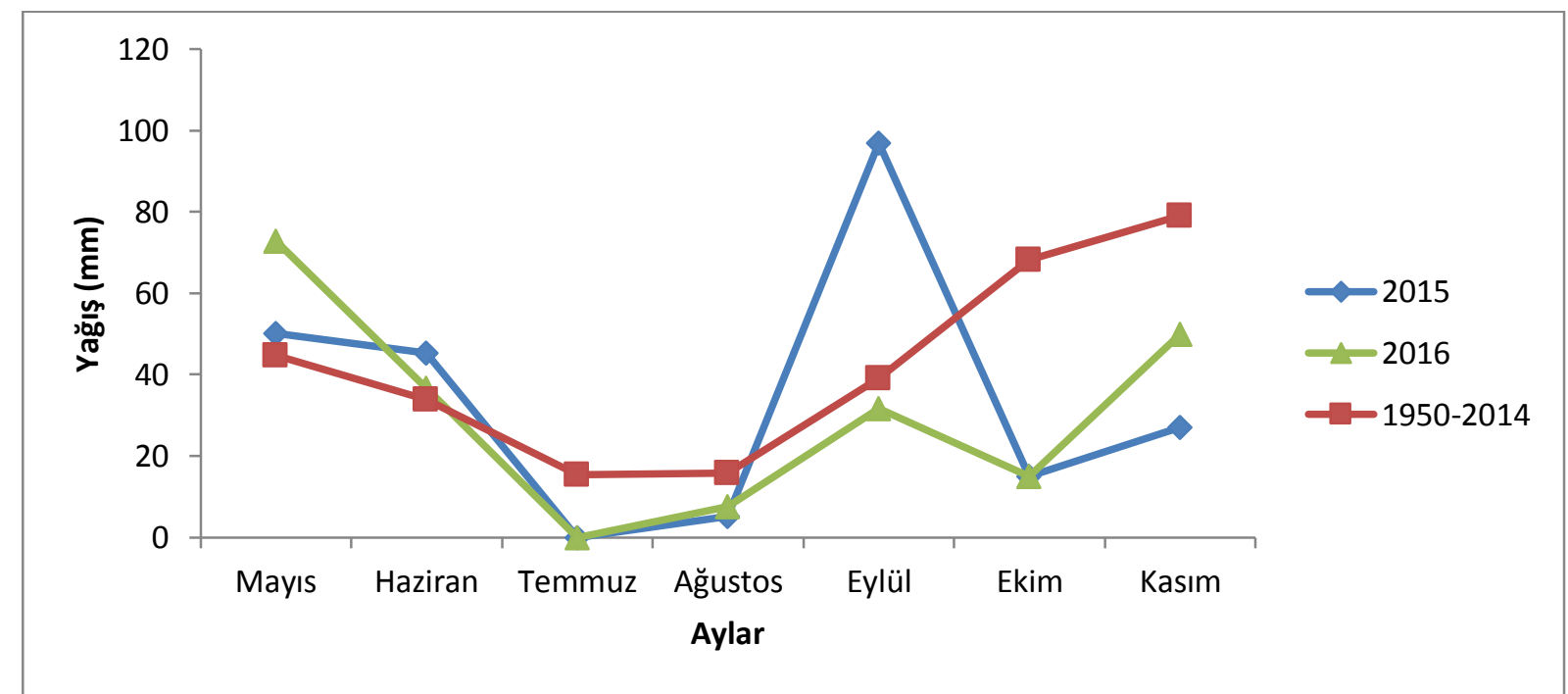

Çizelge 1. Deneme yılı (2015) ve uzun yıllar (1950-2014)'a ait aylık ortalama yağış değerleri

Çizelge 2'de özetlenen sıcaklık değerleri, deneme yılı Haziran ve Temmuz ayları sıcaklarının uzun yıllar ortalamasıyla aynı iken, Ağustos, Eylül ve Ekim aylarında ise yüksek olduğunu ortaya koymaktadır.

Araştırma alanının toprakları killi tınlı, hafif alkali ( $\mathrm{pH} 7.8)$, orta düzeyde kireçli $\left(81 \mathrm{~kg} \mathrm{ha}^{-1}\right)$, tuzsuz $(0.48$ $\left.\mathrm{dSm}^{-1}\right)$, organik madde bakımından orta (\%1.9), toplam azot bakımından fakir $\left(\begin{array}{ll}\% & 0.20\end{array}\right)$ ve potasyumca zengindir (1395 kg ha-1). Deneme alanının $1.5 \mathrm{~m}$ toprak profilinde yapilan gözlemlerde drenaj problemi olmadığı belirlenmiştir. Deneme tarlası düz olup, rakımı 25 m'dir.
Deneme alanının ön bitkisi soyadır. Tarla, sonbaharda kulaklı pullukla işlendikten sonra başka bir işlem yapılmamış, ilkbaharda yaylı tırmık ve diskaro ile toprak ufalanmıştır. Ekim öncesi küçük çapa makinesi ile işlenmiş ve arazi ekime hazır hale getirilmiştir. Ekimden bir gün önce deneme alanı sulanmış, ertesi gün tavlı toprakta açılmış çizilere tohumlar elle ekilmişlerdir. Başka sulama yapılmamıştır. İlkbahar toprak hazırlığı esnasında dekara $25 \mathrm{~kg}$ düşecek şekilde 20-20-0 kompoze gübresinden uygulanmıştır. Yabancı ot mücadelesi gerektikçe el çapasıyla gerçekleştirilmiştir. 


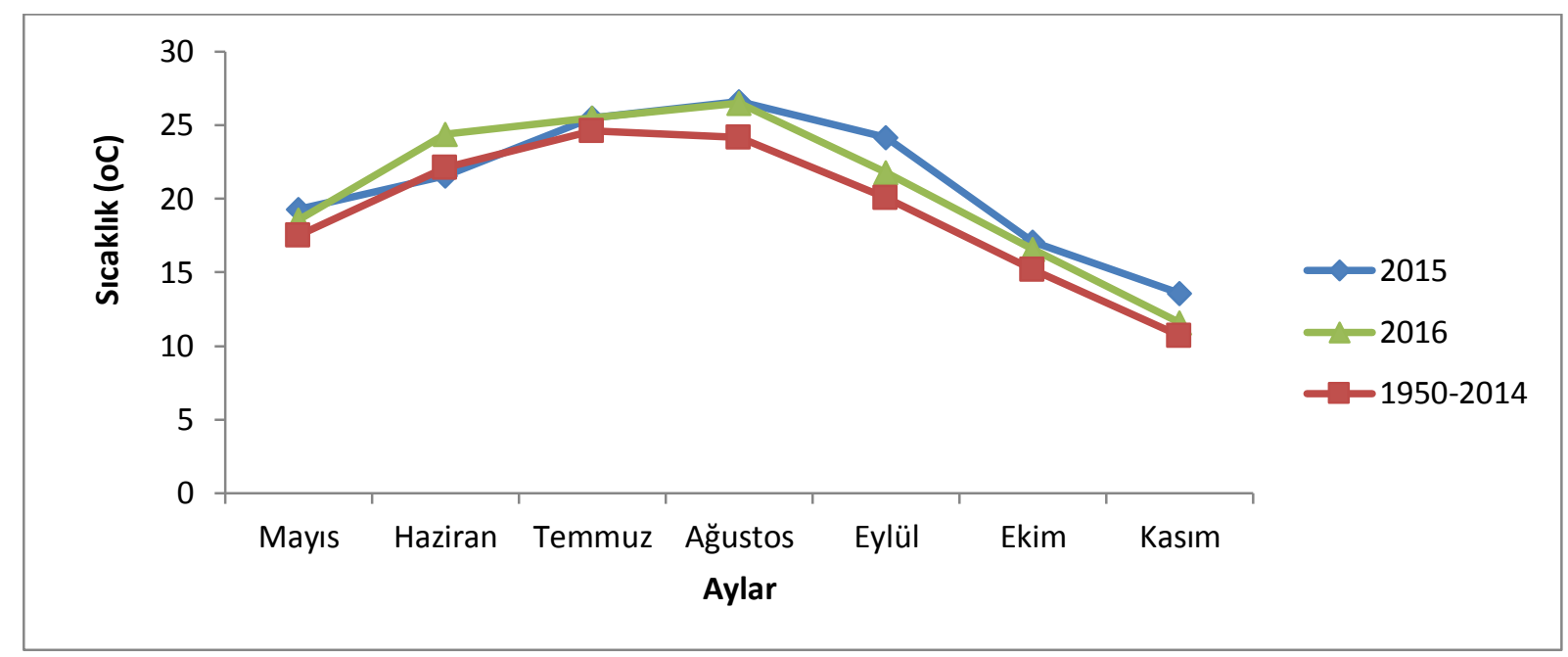

Çizelge 2. Deneme yılı (2015) ve uzun yıllar (1950-2014)'a ait aylık ortalama sıcaklık değerleri

Çalışmada bitki boyu, dal sayısı, bitkide kapsül sayısı, kapsülde tane sayısı, 1000 tane ağırlığı ve tohum verimi değerleri incelenmiştir. Ölçümler, her parselin ikinci ve üçüncü sıralarından rastgele seçilen 10 bitki kullanılarak elde edilmiştir. Hasat edilen bitkiler, tane kaybını ortadan kaldırmak için kapsüllerin kurumaya başladığı dönemde hasat edilmiş ve temiz bir yüzeyde kurutulmaya bırakılmışlar. Tamamen kuruyan kapsüller daha sonra silkelenerek tohum eldesi gerçekleştirilmiştir. SPSS istatistik programı kullanılarak varyans analizi yapılmıştır. Elde edilen iki yılın ortalaması değerler Duncan yöntemine göre gruplandırılmıştır.

\section{BULGULAR VE TARTIŞMA}

İki yılın ortalaması olarak belirlenen ve Tablo 1'de verilen bitki boyu değerleri $121.6-157.5 \mathrm{~cm}$ arasında değişiklik göstermiştir. En yüksek değerler Batem Aksu, Gölmarmara, Orhangazi 99 ve Baydar 2001 çeşitlerinden elde edilmişken (sırasıyla, 157.5, 156.1, 153.3 ve $151.6 \mathrm{~cm}$ ), en düşük değer $121.6 \mathrm{~cm}$ ile Aslanbey ve Osmanlı 99 çeşitlerinde saptanmıştır.

Bitki başına düşen dal sayısı değerleri arasında önemli istatistiki farklar belirlenmiştir. En düşük değer 2.0 adet/bitki ile Aslanbey çeşidinde saptanmışken en yüksek dal sayıları Pakistan hattı ile Boydak, Sarısu ve Tanas çeşitlerinde sayılmıştır (sırasıyla, 6.7, 6.1, 6.0 ve 5.9 adet/bitki).

Bitki başına kapsül sayısı değerleri arasındaki farklar istatistiki anlamda farklı çıkmıştır. En yüksek kapsül sayısını 119.5 adet ile Boydak çeşidi vermişken bu değeri 113.3 adet ile Hatipoğlu, 104.5 adet ile Gölmarmara, 100.5 adet ile Aslanbey ve 99.3 adet ile de Osmanlı 99 çeşitleri izlemiştir. Muganlı 57 çeşidi 65.8 adet ile son sırayı almıştır.

Kapsül başına tohum sayıları çeşitler arasında önemli farklılıklar göstermiş olup, 53.0-67.8 adet/kapsül arasında değişiklik göstermiştir. Gölmarmara, Orhangazi 99, Boydak, Batem Aksu, Tan 99,
Cumhuriyet 99, Aslanbey, Kepsut 99, Baydar 2001 ve Osmanlı 99 çeşitleri aynı istatistiki grup içerisinde yer almışlardır (sırasıyla, 67.8, 67.6, 65.5, 65.0, 63.0, 61.1, $61.0,60.3,60.0$ ve 59.1 adet/bitki).

Önemli bir verim kriteri olan 1000 tane ağırlıkları genotiplere göre değişik değerlere sahip olmuşlardır. 1000 tane ağırlıkları 3.2-4.1 g arasında yer almış olup, en yüksek değerleri veren istatistiki grup $4.1 \mathrm{~g}$ ile Batem Aksu, 4.0 g ile Muganl-57 ve 3.9 g ile Gölmarmara çeşitlerinden meydana gelmiştir. Boydak çeşidi için 3.1 g olarak belirlenen 1000 tane ağırlığı en düşük değer olmuştur.

Bitki boyunun 83.3-112.4 cm, bitki başına dal sayısının 3.0-4.8 adet, bitki başına kapsül sayısının 36.3-59.2 adet, kapsül başına tohum sayısının 50.8-58.8 adet ve 1000 tane ağırlığının da 2.4-3.5 g arasında belirlendiğini bildiren Misganaw ve ark. (2015)'nın bulguları deneme bulgularıyla benzerlikler göstermektedir. Deneme sonuçlarıyla örtüşen sonuçlar bildiren başka araştırmalar da vardır (Uzun ve Çağırgan, 2006; Sumathi ve Muralidharan, 2010; Kurdistani ve Tohidinejad, 2011; Rani ve ark., 2015; Raikwar, 2016). Tohum verimleri $1035-1989 \mathrm{~kg} / \mathrm{ha}$ arasında belirlenmiş olup genotipler arasında istatistiki anlamda farklar bulunmuştur. Boydak, Gölmarmara ve Aslanbey çeşitleri en yüksek değerlerin veren istatistiki grupta yer almışlardır (sırasıyla, 1989, 1968 ve $1753 \mathrm{~kg} / \mathrm{ha}$ ). Çok geç çiçek açan Pakistan yerel hattı ise $1035 \mathrm{~kg} / \mathrm{ha}$ değeri ile büyük bir farkla sonuncu sırayı oluşturmuştur. İran'da gerçekleştirilen denemede, Ramazani (2016)'nin bildirdiği tohum verimi bulguları, deneme bulgularıyla büyük oranda örtüşmektedir. Eryiğit ve ark. (2016)'na göre, bitki boyu 121.0-147.1 cm, dal sayısı 3.6-7.1 adet, bitki başına kapsül sayısı 56.0-125.5 adet, kapsülde tane sayısı 63.5-72.3 adet, 1000 tane ağırlığ 2.8-3.6 g ve tohum verimi değerleri $834.9-1005.8 \mathrm{~kg} / \mathrm{ha}$ arasında yer almışlardır. Tohum verimi $147.2 \mathrm{~kg} / \mathrm{da}$ olarak saptanmıştır (Bhardwaj ve ark., 2014). 
Tablo 1. Susamda incelenen özelliklere ait iki yılın ortalaması değerler.

\begin{tabular}{|c|c|c|c|c|c|c|}
\hline Genotipler & $\begin{array}{l}\text { Bitki boyu } \\
(\mathrm{cm})\end{array}$ & $\begin{array}{c}\text { Dal sayısı } \\
\text { (adet/bitki) }\end{array}$ & $\begin{array}{c}\text { Kapsül } \\
\text { sayıs1 } \\
\text { (adet/bitki) }\end{array}$ & $\begin{array}{c}\text { Kapsülde } \\
\text { tane sayısı } \\
\text { (adet/bitki) }\end{array}$ & $\begin{array}{l}1000 \text { tane } \\
\text { ağırlığ } \\
(\mathrm{g})\end{array}$ & $\begin{array}{l}\text { Tohum } \\
\text { verimi } \\
(\mathrm{kg} / \mathrm{ha})\end{array}$ \\
\hline Gölmarmara & $156.1 \mathrm{a}^{\mathrm{x}}$ & $5.5 \mathrm{~b}-\mathrm{e}$ & $104.5 \mathrm{abc}$ & $67.8 \mathrm{a}$ & 3.9 abc & $1968 \mathrm{ab}$ \\
\hline Boydak & 136.1 defg & $6.1 \mathrm{ab}$ & $119.5 \mathrm{a}$ & $65.5 \mathrm{ab}$ & $3.1 \mathrm{~g}$ & $1989 \mathrm{a}$ \\
\hline Sarısu & $143.0 \mathrm{~cd}$ & $6.0 \mathrm{ab}$ & 89.0 cde & $57.1 \mathrm{~b}-\mathrm{e}$ & 3.7 cde & $1569 \mathrm{~cd}$ \\
\hline Tanas & 140.6 cde & $5.9 \mathrm{abc}$ & $89.3 \mathrm{cde}$ & $53.0 \mathrm{e}$ & $3.5 \mathrm{f}$ & $1477 \mathrm{~cd}$ \\
\hline Muganl1-57 & $138.1 \mathrm{def}$ & $4.6 \mathrm{f}$ & $65.8 \mathrm{e}$ & $57.5 \mathrm{~b}-\mathrm{e}$ & $4.0 \mathrm{ab}$ & $1710 \mathrm{bcd}$ \\
\hline Cumhuriyet 99 & $133.6 \mathrm{efg}$ & $5.1 \mathrm{def}$ & $74.1 \mathrm{de}$ & $61.1 \mathrm{a}-\mathrm{e}$ & 3.7 cde & $1552 \mathrm{~cd}$ \\
\hline Osmanlı 99 & $121.6 \mathrm{i}$ & $4.5 \mathrm{f}$ & $99.3 \mathrm{abc}$ & 59.1 a-e & 3.6 def & $1438 \mathrm{~d}$ \\
\hline Tan 99 & $131.5 \mathrm{fgh}$ & $5.7 \mathrm{bcd}$ & $95.0 \mathrm{bcd}$ & 63.0 a-d & $3.6 \mathrm{def}$ & $1564 \mathrm{~cd}$ \\
\hline Kepsut 99 & $147.3 \mathrm{bc}$ & $4.7 \mathrm{ef}$ & $72.0 \mathrm{de}$ & $60.3 \mathrm{a}-\mathrm{e}$ & $3.7 \mathrm{cde}$ & $1589 \mathrm{~cd}$ \\
\hline Hatipoğlu & $130.1 \mathrm{gh}$ & 5.4 b-e & $113.3 \mathrm{ab}$ & $56.5 \mathrm{cde}$ & 3.7 cde & $1514 \mathrm{~cd}$ \\
\hline Aslanbey & $121.6 \mathrm{i}$ & $2.0 \mathrm{~g}$ & $100.5 \mathrm{abc}$ & $61.0 \mathrm{a}-\mathrm{e}$ & $3.2 \mathrm{~g}$ & $1753 \mathrm{abc}$ \\
\hline Baydar 2001 & $151.6 \mathrm{ab}$ & 4.9 ef & $94.0 \mathrm{bcd}$ & 60.0 a-e & $3.8 \mathrm{bcd}$ & $1728 \mathrm{bc}$ \\
\hline Batem Aksu & $157.5 \mathrm{a}$ & $5.3 b-f$ & $83.0 \mathrm{cde}$ & $65.0 \mathrm{abc}$ & $4.1 \mathrm{a}$ & $1590 \mathrm{~cd}$ \\
\hline Özberk-82 & $138.6 \mathrm{def}$ & $5.2 \mathrm{c}-\mathrm{f}$ & $81.5 \mathrm{cde}$ & $53.5 \mathrm{e}$ & $3.8 \mathrm{bcd}$ & $1660 \mathrm{~cd}$ \\
\hline Orhangazi 99 & $153.3 \mathrm{ab}$ & $5.1 \mathrm{def}$ & $87.5 \mathrm{cde}$ & $67.6 \mathrm{a}$ & 3.6 def & $1711 \mathrm{bcd}$ \\
\hline Pakistan (Hat) & $124.8 \mathrm{hi}$ & $6.7 \mathrm{a}$ & 88.0 cde & $55.8 \mathrm{de}$ & $3.2 \mathrm{~g}$ & $1035 \mathrm{e}$ \\
\hline \multicolumn{7}{|c|}{ Varyans analizi sonuçları } \\
\hline Yillar & $* *$ & $* *$ & $* *$ & $* *$ & öd & $* *$ \\
\hline Genotipler & $* *$ & $* *$ & $* *$ & $* *$ & $* *$ & $* *$ \\
\hline $\begin{array}{ll}\text { Yillar } & \mathrm{x} \\
\text { Genotipler } & \\
\end{array}$ & öd & $* *$ & öd & $* *$ & $* *$ & öd \\
\hline
\end{tabular}

x: Bir sütunda farklı harflerle gösterilen ortalamalar arasında istatistiki önemde farklar vardır. **: 0.01 olasılık düzeyinde önemli, öd: Önemli değil.

\section{KORELASYON KATSAYILARI}

Tohum verimi ile tohum verimine katkı sağlayan karakterler arasındaki ilişki de incelenmiştir. Tablo 2'de verilen bilgilere göre, tohum verimi, bitki boyu, bitki başına kapsül sayısı ve kapsül başına tohum sayısı ile $\% 1$ olasılık düzeyinde pozitif yönde önemli korelasyonlar yapmıştır (sırasıyla, 0.437, 0.382 ve 0.394). Ayrıca bitki boyu ile dal sayısı $\left(0.246^{*}\right)$, kapsül başına tohum sayısı $(0.301 * *)$ ve 1000 tane ağırlığı $\left(0.347^{* *}\right)$ arasında pozitif ve önemli; bitki başına kapsül sayısı (0.027) ise önemsiz ilişkiler saptanmıştır. Dal sayısı ile bitki boyu ve kapsül başına tohum sayısı; bitki başına kapsül sayısı ile kapsül başına tohum sayısı arasında pozitif önemli $\left(0.278^{* *}\right)$ ve 1000 tane ağırlığ arasında negatif önemli $\left(-0.255^{*}\right)$ korelasyon katsayıları hesaplanmıştır.

Tablo 2: İncelenen özellikler arasında belirlenen korelasyon katsayıları

\begin{tabular}{lcccccc} 
Özellikler & $\begin{array}{c}\text { Tohum } \\
\text { verimi }\end{array}$ & Bitki boyu & Dal sayısı & $\begin{array}{c}\text { Bitki başına } \\
\text { kapsül sayısı }\end{array}$ & $\begin{array}{c}\text { Kapsül } \\
\text { başına } \\
\text { tohum sayısı }\end{array}$ & $\begin{array}{c}1000 \text { tane } \\
\text { ağırlığı }\end{array}$ \\
\hline Tohum verimi & 1.00 & $0.437^{* *}$ & -0.001 & $0.382^{* *}$ & $0.394^{* *}$ & 0.009 \\
Bitki boyu & $0.437^{* *}$ & 1.00 & $0.246^{*}$ & 0.027 & $0.301^{* *}$ & $0.347^{* *}$ \\
Dal sayısı & -0.001 & $0.246^{*}$ & 1.00 & 0.184 & $0.232^{*}$ & -0.121 \\
Bitki başına kapsül sayısı & $0.382^{* *}$ & 0.027 & 0.184 & 1.00 & $0.278^{* *}$ & $-0.255^{*}$ \\
Kapsül başına tohum & $0.394^{* *}$ & $0.301^{* *}$ & $0.232^{*}$ & $0.278^{* *}$ & 1.00 & -0.033 \\
sayısı & 0.009 & $0.347^{* *}$ & -0.121 & $-0.255^{*}$ & -0.033 & 1.00 \\
1000 tane ağırlı̆̆ı & & & & & &
\end{tabular}

Eryiğit ve ark. (2016)'na göre, tohum verimi dal sayısı, bitki başına kapsül sayısı, kapsülde tane sayısı ve 1000 tane ağırlığı ile önemli pozitif korelasyonlar yapmıştır şeklindeki bulguları deneme bulgularını desteklemektedir. Yol ve ark. (2010), tohum verimi ile bitki boyu, yan dal sayısı, bitki başına kapsül sayısı, 1000 tane ağırlığ saptamışlardır. Buna ilave olarak, bitki boyu ile yan dal sayısı, bitkide kapsül sayısı, kapsülde tane sayısı ve 1000 tane ağırlığı; yan dal sayısı ile bitkide kapsül sayısı, kapsülde tane sayısı ve 1000 tane ağırlığ1 arasında pozitif önemli korelasyon katsayıları elde etmişlerdir. Muhamman ve ark. (2010), tohum verimi ile bitki boyu arasında pozitif önemli korelasyon katsayıları bulduklarını açıklamışlardır.

\section{SONUC}

Bursa koşullarında tohum verimi bakımından Boydak ve Gölmarmara çeşitleri en yüksek değerleri verdikleri için susam yetiştirmek isteyen üreticilere önerilmektedir. 


\section{KAYNAKLAR}

Alam Sarkar MN, Salim M, Islam N, Rahman MM 2007. Effect of sowing date and time of harvesting on the yield and yield contributing characters of sesame (Sesamum indicum L.) seed. International Journal of Sustainable Crop Production, 2 (6): 3135.

Anonim 2017.

FAO

İstatistikleri http://faostat3.fao.org/download/Q/QC/E

Anonim 2017. TUİK Bitkisel üretim istatistikleri http://www.tuik.gov.tr/Pre Tablo.do? alt_ $\mathrm{id}=1001$

Anonim 2017. 2017 Yilında Yapılacak Tarımsal Teşvikler. Bakanlar Kurulu Kararı http://www.resmigazete.gov.tr/eskiler/2017/08/2017 0818M1-27.pdf

Arslan Ç, Uzun B, Ülger S, Çağırgan Mİ 2007. Determination of oil content and fatty acid composition of sesame mutants suited for intensive management conditions. Journal of American Oil Chemists' Society, 84: 917-920.

Baydar H 2001. Susam (Sesamum indicum L.) genetiği ve 1slahı üzerinde araştırmalar II. İdeal bitki tiplerinin geliştirilmesi, IV. Ulusal Tarla Bitkileri Kongresi, 17-21 Eylül 2001， Sayfa: 117-122, Tekirdağ.

Bhardwaj HL, Hamama AA, Kraemer ME, Langham DR 2014. Cultivars, planting dates, and row spacing effects on sesame seed yield and mineral composition. Journal of Agricultural Science, 6 (9): 1-7.

Eryigit, T, Kaya AR, Tuncturk M, Aldemir R, Yildirim B 2016. Evaluation of some sesame (Sesamum indicum L.) varieties' performances under microclimate conditions of Igdir-Turkey.

VII International Scientific Agriculture Symposium," Agrosym 2016", 6-9 October 2016, Jahorina, Bosnia and Herzegovina. Proceedings, pp. 276-282.

Kurdistani R, Tohidinejad E 2011. Yield potential evaluation and path analysis of different sesame genotypes under various levels of iron. African Journal of Plant Science, 5 (15): 862-866.

Misganaw M, Mekbib F, Wakjira A 2015. Genotype x environment interaction on sesame (Sesamum indicum L.) seed yield. African Journal of Agricultural Research, 10 (21): 2226-2239.
Muhamman MA, Mohammed SG, Lado A, Belel MD 2010. Interrelationship and path coefficient analysis of some growth and yield characteristics in sesame (Sesamum indicum L.). Journal of Agricultural Science, 2 (4): 100-106.

Raikwar, RS 2016. Stability for grain yield and its contributing traits in sesame (Sesamum indicum L.). Electronic Journal of Plant Breeding, 7 (4): 10331039.

Ramazani SHR 2016. Surveying the relations among traits affecting seed yield in sesame (Sesamum indicum L.). Journal of Crop Science and Biotechnology, 19 (4): 303-309.

Rani TS, Laxman S, Thippeswamy S, Kiranbabu T, Venkataiah M, Rao MP 2015. Genetic studies for the exploitation of heterosis in sesame (Sesamum indicum $\mathrm{L}$.). SABRAO Journal of Breeding and Genetics, 47 (3): 231-237.

Silme RS, Çağırgan İ 2009. Seçilmiş mutant ve dünya susam materyalinin verim ve verim komponentleri bakımından değerlendirilmesi. X. Ulusal Nükleer Bilimler ve Teknolojileri Kongresi, 6-9 Ekim 2009, 333-339.

Sumathi P, Muralidharan V 2010. Analysis of genetic variability, association and path analysis in the hybrids of sesame (Sesamum indicum L.). Tropical Agricultural Research Extension, 13 (3): 63-67.

Şahin G 2014. Türkiye'de üretimi azalan önemli bir yăg bitkisi susam. İnsan ve Toplum Bilimleri Araştırmaları Dergisi, Apr/May, 3 (2): 404-433.

Tan AŞ 2011. Bazı Susam Çeşitlerinin Menemen Koşullarında Performansları. Anadolu, 21 (2): 1128.

Uzun B, Çağırgan Mİ 2006. Comparison of determinate and indeterminate lines of sesame for agronomic traits. Field Crops Research, 96: 13-18.

Uzun B, Arslan Ç, Furat Ş 2008. Variation in fatty acid compositions, oil content and oil yield in a germplasm collection of sesame (Sesamum indicum L.). Journal of American Oil Chemists' Society, 85: 1135-1142.

Yol E, Karaman E, Furat S, Uzun B 2010. Assessment of selection criteria in sesame by using correlation coefficients, path and factor analyses. Australian Journal of Crop Science, 4 (8): 598-602. 